NASA/TM-2001-210988

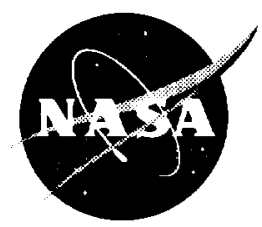

Damage Assessment of Creep Tested and Thermally Aged Udimet 520 Using Acousto-Ultrasonics

Andrew L. Gyekenyesi

Ohio Aerospace Institute, Brook Park, Ohio

Harold E. Kautz

Glenn Research Center, Cleveland, Ohio

Wei Cao

West Virginia Institute of Technology, Montgomery, West Virginia 
The NASA STI Program Office ... in Profile

Since its founding, NASA has been dedicated to the advancement of aeronautics and space science. The NASA Scientific and Technical Information (STI) Program Office plays a key part in helping NASA maintain this important role.

The NASA STI Program Office is operated by Langley Research Center, the Lead Center for NASA's scientific and technical information. The NASA STI Program Office provides access to the NASA STI Database, the largest collection of aeronautical and space science STI in the world. The Program Office is also NASA's institutional mechanism for disseminating the results of its research and development activities. These results are published by NASA in the NASA STI Report Series, which includes the following report types:

- TECHNICAL PUBLICATION. Reports of completed research or a major significant phase of research that present the results of NASA programs and include extensive data or theoretical analysis. Includes compilations of significant scientific and technical data and information deemed to be of continuing reference value. NASA's counterpart of peerreviewed formal professional papers but has less stringent limitations on manuscript length and extent of graphic presentations.

- TECHNICAL MEMORANDUM. Scientific and technical findings that are preliminary or of specialized interest, e.g., quick release reports, working papers, and bibliographies that contain minimal annotation. Does not contain extensive analysis.

- CONTRACTOR REPORT. Scientific and technical findings by NASA-sponsored contractors and grantees.
- CONFERENCE PUBLICATION. Collected papers from scientific and technical conferences, symposia, seminars, or other meetings sponsored or cosponsored by NASA.

- SPECIAL PUBLICATION. Scientific, technical, or historical information from NASA programs, projects, and missions, often concerned with subjects having substantial public interest.

- TECHNICAL TRANSLATION. Englishlanguage translations of foreign scientific and technical material pertinent to NASA's mission.

Specialized services that complement the STI Program Office's diverse offerings include creating custom thesauri, building customized data bases, organizing and publishing research results ... even providing videos.

For more information about the NASA STI Program Office, see the following:

- Access the NASA STI Program Home Page at http://www.sti.nasa.gov

- E-mail your question via the Internet to help@sti.nasa.gov

- Fax your question to the NASA Access Help Desk at 301-621-0134

- Telephone the NASA Access Help Desk at $301-621-0390$

- Write to: NASA Access Help Desk NASA Center for AeroSpace Information 7121 Standard Drive Hanover, MD 21076 
NASA/TM-2001-210988

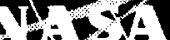

Damage Assessment of Creep Tested and Thermally Aged Udimet 520 Using Acousto-Ultrasonics

Andrew L. Gyekenyesi

Ohio Aerospace Institute, Brook Park, Ohio

Harold E. Kautz

Glenn Research Center, Cleveland, Ohio

Wei Cao

West Virginia Institute of Technology, Montgomery, West Virginia

Prepared for the

Turbo Expo 2001

cosponsored by the American Society of Mechanical Engineers and the International Gas Turbine Institute

New Orleans, Louisiana, June 4-7, 2001

National Aeronautics and

Space Administration

Glenn Research Center 


\section{Acknowledgments}

The authors would like to acknowledge Dr. George Y. Baaklini of the NASA Glenn Research Center as well as the Aviation Safety Program for providing the funding for this study. In addition, the authors thank Mr. Robert E. Shannon of Siemens Westinghouse Power Company, Science and Technology Center, for supplying the aged and creep tested specimens.

Available from

NASA Center for Aerospace Information 7121 Standard Drive

Hanover, MD 21076
National Technical Information Service 5285 Port Royal Road Springfield, VA 22100

Available electronically at http://gltrs.grc.nasa.gov/GLTRS 


\title{
DAMAGE ASSESSMENT OF CREEP TESTED AND THERMALLY AGED UDIMET 520 USING ACOUSTO-ULTRASONICS
}

\author{
Andrew L. Gyekenyesi \\ Ohio Aerospace Institute \\ Brook Park, Ohio 44142 \\ Harold E. Kautz \\ National Aeronautics and Space Administration \\ Glenn Research Center \\ Cleveland, Ohio 44135 \\ Wei Cao \\ West Virginia University Institute of Technology \\ Montgomery, West Virginia 25136
}

\begin{abstract}
Due to elevated temperatures and excessive stresses, turbine components may experience creep behavior. As a result, it is desirable to monitor and assess the current condition of such components. This study employed the Acousto-Ultrasonics (AU) method in an effort to monitor the state of the material at various percentages of used up creep life in the nickel base alloy, Udimet 520. A stepped specimen (i.e., varying cross sectional area) was employed which allowed for a post mortem nondestructive evaluation (NDE) analysis of the various levels of used up life. The overall objectives here were two fold: First. a user friendly, graphical interface $\mathrm{AU}$ system was developed, and second the new $\mathrm{AU}$ system was applied as an NDE tool to assess distributed damage resulting from creep. The experimental results demonstrated that the AU method shows promise as an NDE tool capable of detecting material changes as a function of used up creep life. Furthermore, the changes in the AU parameters were mainly attributed to the case of combined load and elevated temperature (i.e., creep) and not simply because of a timed exposure at elevated temperature (i.e., heat treatment or thermal aging).
\end{abstract}

\section{INTRODUCTION}

In recent years emphasis has been placed on the early detection of material changes experienced in turbine power plant components. During the scheduled overhaul of a turbine, the current techniques of examination of various hot section components aim to find flaws such as cracks, wear and erosion, as well as excessive deformations. Thus far, these localized damage modes have been detected with satisfactory results. 'However, the techniques used to find these flaws provide no information on life until the flaws are actually detected. Major improvements in damage assessment, safety, as well as more accurate life prediction could be achieved if nondestructive evaluation (NDE) techniques can be utilized to sense material changes that occur prior to the localized defects mentioned above.
Due to elevated temperatures and applied stresses, turbine components are subject to creep processes that limit the components' life. For polycrystalline metals, the permanent deformations associated with creep are due to various stress assisted, thermally activated micromechanisms. These include the generation and mobilization of dislocations, escape of dislocations from their glide planes, grain boundary sliding and diffusion of atoms and point defects. ${ }^{2}$ These mechanisms characterize the majority of the creep life as defined by the primary and secondary portions of a typical strain versus time creep curve. As failure approaches, an increase in strain rate is noticed and is identified as the tertiary portion of the creep curve. The increase in the strain rate is assumed to occur due to additional mechanisms such as the growth and accumulation of cavities along grain boundaries. The growing cavities reduce the effective area of the material with the final result being creep rupture. For a full discussion of creep behavior, the reader is advised to consult the textbook by Shames and Cozzorelli ${ }^{2}$ as well as the textbook by Gittus. ${ }^{3}$

The goal of this study was to employ an NDE technique that discloses distributed material changes that occur prior to the localized damage detected by the current methods of inspection. The creep processes were the life limiting condition of interest and the NDE technique utilized was Acousto-Ultrasonics (AU). AU is an NDE technique that utilizes two ultrasonic transducers to interrogate the condition of a test specimen. The sending transducer introduces an ultrasonic pulse at a point on the surface of the specimen while a receiving transducer detects the signal after it has passed through the material. The aim of the method is to correlate certain parameters of the detected waveform to characteristics of the material between the two transducers. Here, the waveform parameter of interest is the attenuation due to internal damping for which information is being garnered from the frequency domain. The parameters utilized to indirectly quantify the attenuation are the ultrasonic decay rate as well as various moments of the frequency power spectrum. ${ }^{-6}$ To attain the 
objective of an NDE technique that can monitor distributed damage due to creep, a new, user-friendly, graphical interface, AU system was developed at NASA Glenn Research Center. The AU system is a multifunction system that captures and digitizes the signal from the receiving ultrasonic transducer and then conducts post-test signal analysis. The system's post processing software calculates multiple parameters utilized to study the material of interest.

Creep tests were conducted on the nickel base alloy, Udimet 520 . $\mathrm{AU}$ measurements were performed at various percentages of used up life. Rather than periodically interrupting the creep tests to obtain AU data, a stepped specimen (i.e., a varying cross sectional gage area) was employed. This specimen design allowed the creep tests to continue, uninterrupted. until creep rupture occurred. The failure occurred in the smallest cross sectional area. Each specimen had four different cross sectional areas within the gage section, each of which corresponded to a different level of used up life. The following section describes the specimen design, the $A U$ system, as well as the experimental procedure.

Lastly. it should be noted that the vast majority of research concerning the $\mathrm{AU}$ technique has been based on characterizing damage in composite materials (e.g., polymer matrix composites, ceramic matrix composites, etc.). For the most part, the distributed damage in composites is in the form of fiber-matrix debonding (interface failure), matrix cracking that can be intralaminar or interlaminar (delaminations), and fiber fracture or fiber micro-buckling. ${ }^{7}$ These types of damage mechanisms are known to be highly attenuating. It is much more challenging to gage the microstructural evolution that occurs in monolithic metallic alloys during creep. The change in attenuation resulting from distributed damage in metals is significantly lower than that seen in most composites.

\section{EXPERIMENTAL METHODS}

The material utilized for this study was Udimet 520, a nickel base alloy. Creep specimens were designed with a multi-step gage region to provide areas of different remaining life (see Figure 2 in the Results section for a photograph of a fractured specimen). The overall length of the specimens was $15 \mathrm{~cm}$ (6 in.); each step as well as the grip sections had a length of $2.5 \mathrm{~cm}(1 \mathrm{in}$.). The thickness was $0.4 \mathrm{~cm}$ $(0.16 \mathrm{in}$.). The four gage widths ranged from 2.25 to $3.0 \mathrm{~cm}(0.9$ to 1.2 in.) and were designed to correspond to $12.5,25,50$, and 100 percent used up life with fracture occurring in the cross-section of smallest area. Note that life was defined as time to complete fracture for a given fixed load. The applied loads for each specimen were selected by reviewing conventional creep data for this particular material. ${ }^{8}$ Specimens were stressed at various levels at $732{ }^{\circ} \mathrm{C}$ $\left(1350^{\circ} \mathrm{F}\right)$ and at $816^{\circ} \mathrm{C}\left(1500^{\circ} \mathrm{F}\right)$. Tables 1 and 2 summarize the test matrix as well as the results. Furthermore, specimens were thermally aged (i.e., at temperature with no load) and interrogated by the AU method. This was done so as to compare AU results of creep tested specimens with AU results relating to thermally aged specimens. A total of nineteen specimens were provided for the AU analysis; eight specimens were creep tested, ten specimens were thermally aged at temperatures and times corresponding to the creep conditions, and one specimen was tested in the as received condition (i.e., the baseline specimen). Lastly, it should be noted that the goal here was to provide creep tested specimens with various levels of used up life for NDE analysis utilizing the new AU system. This particular material has been fully characterized in reference 8 . Therefore, in-depth details of the material behavior are not discussed here.
Table 1. Creep Specimen Test Matrix and Results at $732^{\circ} \mathrm{C}$

\begin{tabular}{|l|l|l|l|l|}
\hline Predicted life, hrs & 100 & 200 & 400 & 800 \\
\hline Stress: $100 \%$ used up life, MPa & 522 & 483 & 447 & 413 \\
\hline Stress: $50 \%$ used up life, MPa & 483 & 447 & 413 & 382 \\
\hline Stress: $25 \%$ used up life, MPa & 447 & 413 & 382 & 354 \\
\hline Stress: $12.5 \%$ used up life, MPa & 413 & 382 & 354 & 327 \\
\hline Creep failure time ${ }^{* *}$, hrs & 260 & 321 & 745 & 1395 \\
\hline Failure strain $\%$ \% & 5.6 & 5.3 & 9.1 & 8.6 \\
\hline Specimen ID & $\mathrm{A} 1$ & $\mathrm{Cl}$ & $\mathrm{B} 1$ & $\mathrm{~B} 2$ \\
\hline
\end{tabular}

"Predicted time to creep failure for smallest area gage section and stresses for the multiple gage widths were based on the conventional creep data of reference 8 .

${ }^{*}$ Creep failure time and failure strain are actual results for the $100 \%$ used up creep life gage sections of the specimens tested here.

Table 2. Creep Specimen Test Matrix and Results at $816^{\circ} \mathrm{C}$

\begin{tabular}{|l|l|l|l|l|}
\hline Predicted life, hrs & 100 & 200 & 400 & 800 \\
\hline Stress: $100 \%$ used up life, MPa & 419 & 374 & 334 & 330 \\
\hline Stress: $50 \%$ used up life, MPa & 387 & 346 & 310 & 305 \\
\hline Stress: $25 \%$ used up life, MPa & 359 & 321 & 286 & 282 \\
\hline Stress: $12.5 \%$ used up life, MPa & 332 & 296 & 265 & 261 \\
\hline Creep failure time, hrs $^{* *}$ & 23 & 56 & 144 & 705 \\
\hline Failure strain $\%$ & 9.6 & 5.6 & 10.9 & 11.0 \\
\hline Specimen ID & $\mathrm{C} 2$ & $\mathrm{D} 1$ & $\mathrm{D} 2$ & $\mathrm{~A} 2$ \\
\hline
\end{tabular}

Predicted time to creep failure for smallest area gage section and stresses for the multiple gage widths were based on the conventional creep data of reference 8 .

${ }^{* *}$ Creep failure time and failure strain are actual results for the $100 \%$ used up creep life gage sections of the specimens tested here.

As stated earlier, the fundamental aspect of the $\mathrm{AU}$ method entails introducing a mechanical excitation at one point on a material surface and sensing the resulting disturbance at another spot on the material surface. ${ }^{9-1 T}$ Figure 1 displays a general diagram of the AU experimental set-up employed for this study. The method of excitation involved the utilization of piezoelectric transducers. A pulsing transducer was used to introduce a high-frequency, broadband ultrasonic pulse into the specimen. The ultrasonic pulse was allowed to distribute itself diffusely into the specimen. The term diffuse relates to an incoherent ultrasonic wave which has lost all phase information. A diffuse wave is a complicated superposition of wave modes and sample reverberations that resembles an acoustic emission signal. This is somewhat different than traditional ultrasonics where a welldefined acoustic pulse is monitored. The decay of this resulting incoherent field is then examined as a function of frequency. 5,6

Typically in AU, two separate transducers are applied at some fixed separation on the face of the specimen. An ultrasonic wave is introduced and allowed to propagate along the length of the specimen. The fact that the characterization can be directed along the primary load direction in structures indicates an important advantage of this technique over typical ultrasonic techniques (e.g.. C-scan). Because the sub-areas (defining the various levels of used up life; see above) of the creep specimens were relatively small with respect to the size of a typical transducer, a dual element transducer was utilized (see Figure 1). The dual element transducer had a single body construction 


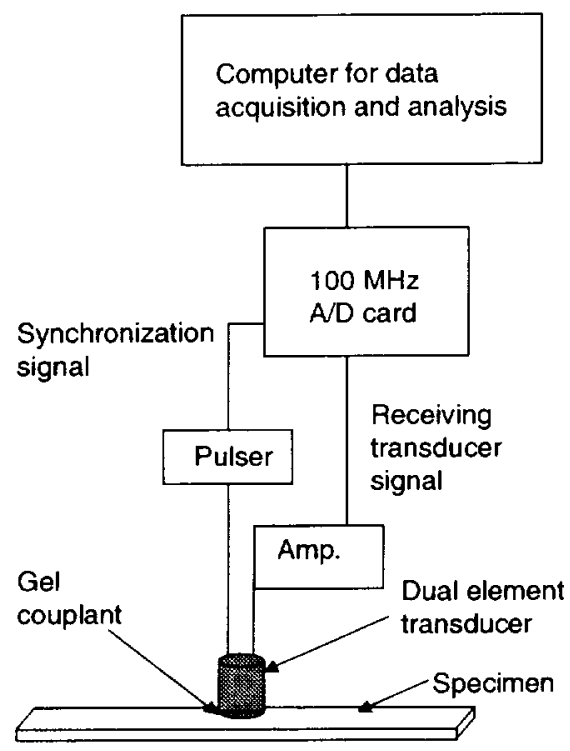

Figure 1. Schematic of AU set-up.

that contained two independent piezoelectric elements separated by an acoustic shield. Hence, one piezoelectric element acted as the pulser and the other acted as the receiver. The $2.25 \mathrm{MHz}$ broadband, dual element transducer employed for this study had a $6 \mathrm{~mm}(0.25 \mathrm{in})$ diameter contact area and was manually joined to the specimen using a gel couplant. The shape of the contact area for each individual piezoelectric element within the single transducer body was a halfcircle. Furthermore, the transducer was aligned perpendicular to the face of the specimen (see Figure 1). The computer's data acquisition rate was set to $50 \mathrm{MHz}$ and the acquisition time window was $10 \mu \mathrm{sec}$ (496 data points). The experimental variables were selected after numerous trials that were conducted for optimizing the received signal. By observing the received signals during the trials, one can adjust and optimize certain parameters such as the transducer frequency, signal amplitude, and time duration. One optimization condition was concerned with selecting a high enough frequency so as to localize the ultrasonic signal to the specimen position of interest. When conducting the tests, the piezoelectric elements were aligned to produce an ultrasonic wave path in the length direction of the specimen. The results included four measurements for any given longitudinal position on the specimen. The four conditions of the measurements involved studying each face of the specimen as well as rotating the transducer 180 degrees. For each creep specimen, eighteen positions were analyzed along the centerline in the length direction. Next, a discussion relating to the methods of post-test signal analysis is presented.

Two main approaches for analyzing the received diffuse signal are utilized in the newly developed AU system. First to be discussed is the analysis method that is utilized at NASA GRC. ${ }^{4.6 .12}$ Titled the diffuse field decay rate, the method involves quantifying the internal damping of vibrational energy in materials. The analysis is based on the premise that a diffuse ultrasonic field in an isolated sample will decay only from internal absorption mechanisms and that contributions of damping by air, transducers, and fixturing are minimal. Damping is measured through determination of the volume averaged decay rate of the ultrasonic field as a function of frequency and time. A greater decay rate indicates a greater amount of internal damping. Determining the decay rate is accomplished by dividing the recorded waveform into a number of time windows (eight windows were utilized for this study), after which Fast Fourier Transforms are performed to obtain the power spectrums. Note that the power spectrum is the square of the amplitude function at a given frequency. The total energy of each time window is calculated using the power spectrum (i.e., the area under the power spectrum plot). Further refinement is achieved by obtaining the energy content of various frequency windows within the power spectrums. Lastly, an exponential decay curve is fitted to the plot of energy versus time window. The exponent in the equation is defined as the diffuse field decay rate. Mathematically the equation is expressed as follows:

$$
M_{0}\left(f_{\text {lis }}, f_{\text {high }}, t\right)=\alpha\left(f_{l o w}, f_{\text {high } h}\right) e^{-\beta\left(f_{\text {irm }} \cdot f_{\text {high }}\right) t}
$$

where $t$ is time; $f_{\text {low }}$ and $f_{\text {high }}$ are the low and high frequency filter limits: $M_{0}$ is the mean square value of the power spectrum as a function of frequency and time; $\alpha$ is the intercept as a function of frequency (this value is not utilized in this study): and $\beta$ is the diffuse field decay rate as a function of frequency.

The second method of post processing involves working with the entire time domain signal and again conducting a FFT in order to obtain the power spectrum. ${ }^{12}$ Certain parameters concerning the power spectrum were shown to be sensitive to various types of damage in composite materials. ${ }^{5,13}$ Called the shape parameters, the general equations are defined as follows:

$$
S_{r, k}=\frac{M_{r}}{M_{r-k} f_{c}^{k}} \quad \begin{aligned}
& k=1,2,3 \ldots \\
& r>k
\end{aligned}
$$

where

$$
M_{r}=\int_{f_{\text {ion. }}}^{f_{\text {high }}} S(f) f^{\prime} d f
$$

$S(f)$ is the power spectral density, $f$ is the frequency and $f_{c}$ is the location of the centroid found by the following expression:

$$
f_{c}=\frac{M_{1}}{M_{0}}
$$

Several of the moments and moment ratios can be given physical interpretations. For example, $M_{0}$ is the mean square value of the power spectral density (i.e., the area under the power spectrum). In addition,

$$
f_{0}=\left(\frac{M_{2}}{M_{0}}\right)^{\frac{1}{2}}
$$

is the frequency of mean crossings with positive slopes and

$$
f_{p}=\left(\frac{M_{4}}{M_{2}}\right)^{\frac{1}{2}}
$$


is the frequency of maxima in the time domain. Note that equations (2) through (6) provide scalar values that capture the general characteristics of the power spectrum function. The diffuse field decay rate as well as $M_{o}, f_{c}, f_{o}$, and $f_{p}$ were implemented in the new AU software and were used in this study to assess the creep tested and thermally aged material.

\section{RESULTS}

The time to fracture results as a function of stress and temperature are presented in Tables 1 and 2. Each of the creep specimens fractured in the middle of the narrowest gage section, representing 100 percent used up creep life. Figure 2 displays the $\mathrm{AU}$ data for a creep specimen tested at $732^{\circ} \mathrm{C}\left(1350^{\circ} \mathrm{F}\right)$. To allow for the simultaneous viewing of the multiple parameters, each $\mathrm{AU}$ parameter was normalized by its respective position 18 value. These normalization values were located in the widest gage section of the specimen (i.e., the 12.5 percent used up life region). The error bars in the plots represent one standard deviation of the four repetitive measurements at each position. In addition, a photo of a creep specimen is displayed adjacent to the plots to indicate the longitudinal position of each of the data points. Positions 1-4, 5-9, 10-14, and 15-18, corresponded to $100,50,25$, and 12.5 percent used up creep life, respectively. For this particular specimen, the fracture occurred between positions 2 and 3 in the plots. Figure 2 shows that essentially all the parameters for this particular specimen indicated a functional dependence on position (i.e., used up creep life or damage). These included the diffuse field decay rate, $M_{\theta}$, $f_{c}, f_{0}$, and $f_{p}$, although, the diffuse field decay rate and $M_{0}$ were limited to changes observed near the fracture surface. After experimenting with various frequency filtering windows, the best results were obtained when applying a frequency window from 1.9 to $2.9 \mathrm{MHz}$. This window corresponded to the central frequency of the broadband transducer. Hence, the majority of the ultrasonic energy was located within this window, thereby, increasing the signal to noise ratio. Although utilizing the frequency window drastically reduced data scatter and strengthened the relationship between the parameters and the used up creep life, it did institute the mathematical loss of identity between $f_{c}, f_{0}$, and $f_{p}$. The smaller the frequency window, the more these parameters behaved alike. Lastly, there appeared to be a skewing of the $\mathrm{AU}$ values at the transition regions between each of the gage areas. This is evident by viewing Figure 2 (b) and noting the sloping pattern within each gage area.

The data shown in Figure 2 indicates that there was an overall increase in attenuation of the ultrasonic signal with accumulated damage (i.e., used up creep life), as expected. This was reflected in the increased diffuse field decay rate as well as the decreased ultrasonic wave energy, $M_{0}$. Another effect of the creep damage was the preferential attenuation of the signal's low frequency components. This behavior caused $f_{c}, f_{0}$, and $f_{p}$ to increase with creep damage. Similar trends were observed for all the AU parameters in each of the eight creep specimens, regardless of the applied stress or temperature.

It is observed in Figure 2(b) that $f_{c}, f_{0}$, and $f_{p}$ had the least scatter and highest degree of correlation to used up creep life. Again, this was the case for all the creep specimens. Therefore to simplify the presentation of the data, from this point forward the results are focused on analyzing $f_{c}$, the centroid of the power spectrum. Figure 3 displays $f_{c}$ as a function of position for each of the eight creep specimens. The specimens with the strongest dependence on used up creep life were $\mathrm{Cl}$ and $\mathrm{B} 2$ at $732^{\circ} \mathrm{C}\left(1350^{\circ} \mathrm{F}\right)$ and $\mathrm{C} 2$ at $816^{\circ} \mathrm{C}\left(1500^{\circ} \mathrm{F}\right)$. The rest of the specimens captured only the late stage material changes seen in the vicinity of the failure surface. Lastly, specimen B1 appeared to standout in comparison to the other specimens. No explanation can be given at this time on why specimen Bl was an outlier. Concerning specimen Bl, it was apparent from the start (i.e., 12\% used up life: positions $15-18$ ) that the values for $f_{c}$ were high compared to the other specimens.

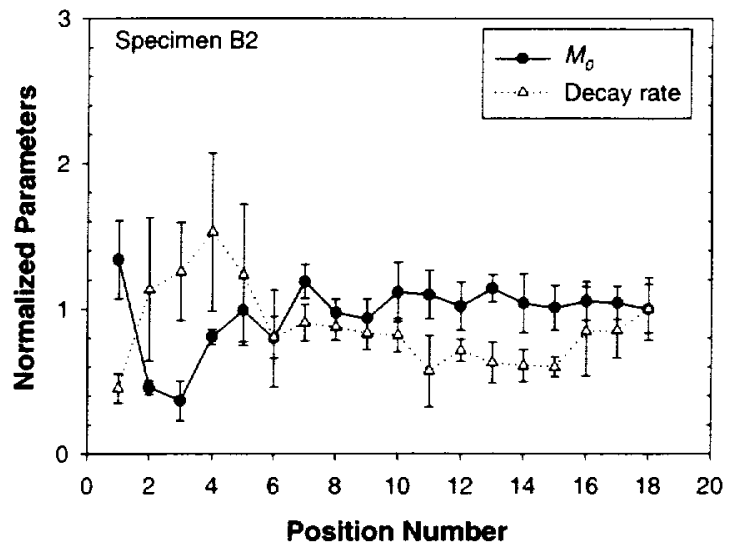

(a)

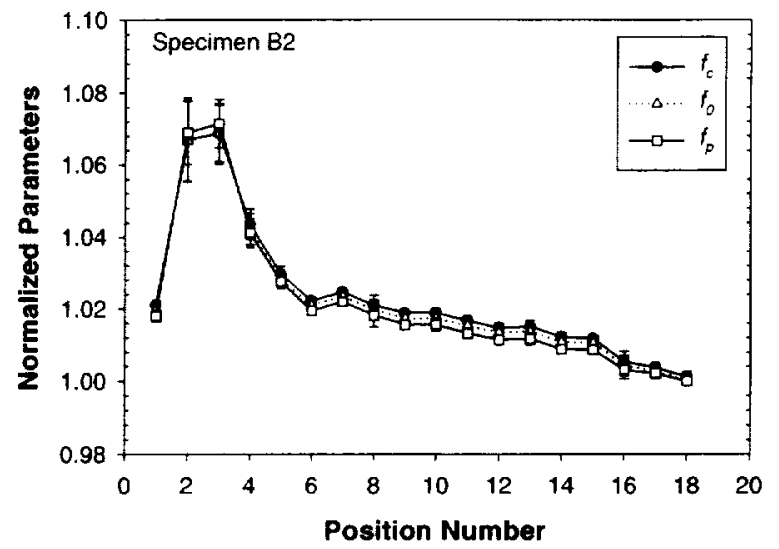

(b)

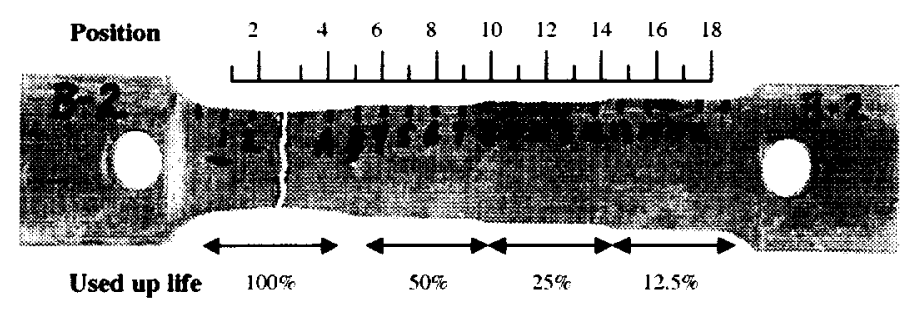

(c)

Figure 2. AU parameters as functions of used up creep life (specimen $\mathrm{B} 2$ tested at $732{ }^{\circ} \mathrm{C}$ ): (a) $M_{0}$ and decay rate; (b) $f_{c}$, $f_{0}$, and $f_{p}$; and (c) photograph of fractured specimen. The four gage areas on the specimen represent from left to right, 100, 50, 25, 12.5 percent used up creep life. Note that the specimen photo is approximately in line with the positions indicated in the graphs. (Use scale above the specimen for position location). 


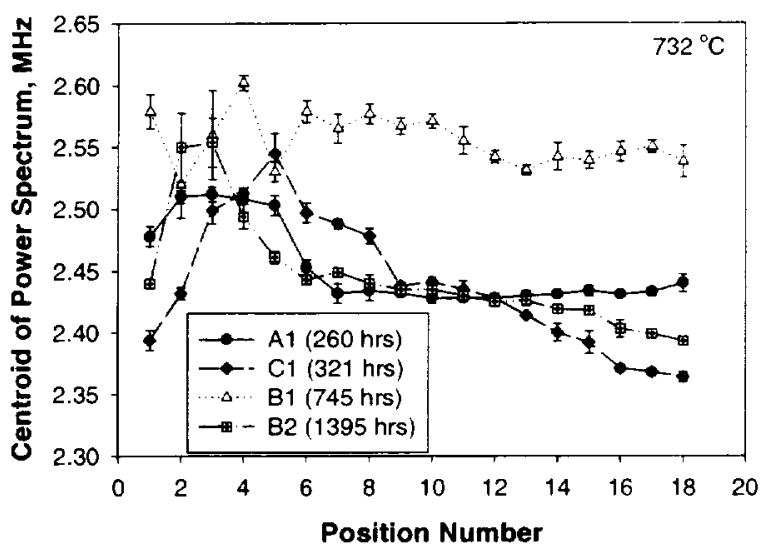

(a)

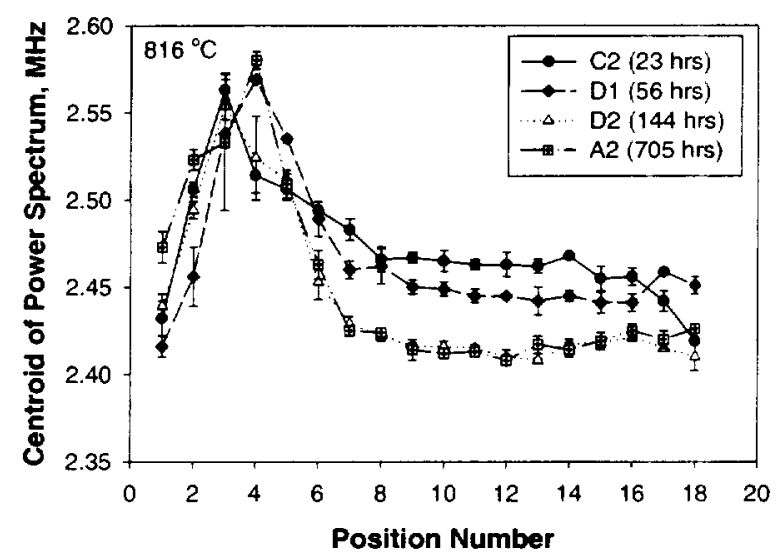

(b)

Figure 3. Centrold of power spectrum $\left(f_{c}\right)$ as a function of specimen position (see Figure 2(c)) for each of the eight creep specimens at (a) $732{ }^{\circ} \mathrm{C}$ and (b) $816^{\circ} \mathrm{C}$. Indicated in the legend is the time to failure for each specimen. Note that all fractures occurred between positions 2 and 5 .

For the eight creep specimens, the average change from the minimum to maximum $f_{c}$ was 6.0 percent. The minimum $f_{c}$ values were located in the largest gage areas (i.e., the gage areas representing 12.5 percent used up creep life) while the maximum $f_{c}$ values were adjacent to the fracture surfaces. The average standard deviation of the four repetitions at each location for all eight specimens ( 144 positions) was 0.25 percent. The overall change in $f_{c}$ was 24 times larger than the average standard deviation of the repetitive measurements. This was a good result considering that for each of the four repetitions the transducer was manually removed and reapplied (see Experimental Methods section).

In an effort to quantify the sensitivity of the $\mathrm{AU}$ method, the centroid of the power spectrum was plotted as a function of used up creep life as shown in Figure 4. For this analysis, the data collected in the 100 percent life region were discarded due to the proximity to the failure surface and the gross damage associated with it. Only the 50. 25 , and 12.5 percent regions were studied. Next, linear regression curves were fitted to the data for each of the eight specimens. The specimens were treated individually due to the obvious specimen-to-

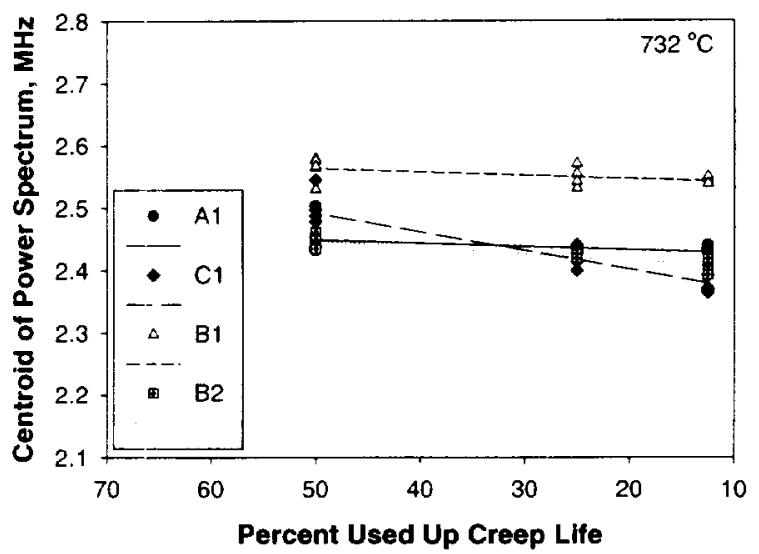

(a)

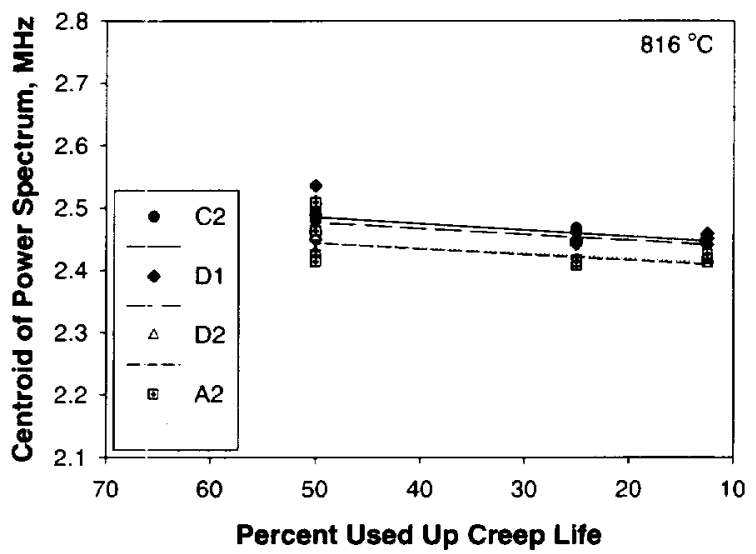

(b)

Figure 4. Centroid of power spectrum $\left(f_{c}\right)$ as a function of used up creep life for each of the eight creep specimens at (a) $732{ }^{\circ} \mathrm{C}$ and (b) $816^{\circ} \mathrm{C}$. The lines represent linear regression fits conducted individually for each of the specimens. Table 3 contains the regression coefficients.

specimen variations seen in Figure 3 . Table 3 contains the linear regression coefficients. The $R^{2}$ value in Table 3 represents a measure of the strength of the relationship between the centroid and the used up creep life. ${ }^{14}$ As can be seen from the results of Table 3, only the specimens $\mathrm{C} 1, \mathrm{~B} 2$, and $\mathrm{C} 2$ indicated statistically relevant relationships between the AU data and the creep damage for the 12.5 to 50 percent life range. Even so, a general trend of an increasing centroid with creep damage was apparent for all the specimens except for specimens $\mathrm{Al}$ and $\mathrm{B} 1$. The specimens $\mathrm{C1}, \mathrm{B} 2$, and $\mathrm{C} 2$ were also able to distinguish between 12.5 and 25 percent used up creep life with 98 percent confidence, utilizing the student t-test ${ }^{14}$. The statistical results indicated the need to conduct further tests on specimens that contain a damage level between 50 and 100 percent used up creep life. Such specimens would enable the full characterization of the AU sensitivity concerning creep damage. It should be noted that some error was probably introduced in these calculations as a result of the overlapping damage or skewness that occurred within and adjacent to the transition areas between the multiple gage sections. 
Table 3. Linear Regression Coefficients for Figure 4

\begin{tabular}{|c|l|l|l|}
\hline Specimen & \multicolumn{1}{|c|}{$\begin{array}{c}\text { Intercept, } \\
\mathrm{MHz}\end{array}$} & $\begin{array}{c}\text { Slope } \times 10^{-3}, \\
\mathrm{MHz} / \text { Percent }\end{array}$ & $\mathrm{R}^{2}$ \\
\hline $\mathrm{A} 1$ & 2.42 & 0.52 & 0.18 \\
\hline $\mathrm{C} 1$ & 2.34 & 2.99 & 0.79 \\
\hline $\mathrm{B} 1$ & 2.54 & 0.58 & 0.29 \\
\hline $\mathrm{B} 2$ & 2.39 & 1.05 & 0.76 \\
\hline $\mathrm{C} 2$ & 2.43 & 1.01 & 0.60 \\
\hline $\mathrm{D} 1$ & 2.42 & 0.94 & 0.35 \\
\hline $\mathrm{D} 2$ & 2.40 & 0.91 & 0.29 \\
\hline $\mathrm{A} 2$ & 2.40 & 0.80 & 0.23 \\
\hline
\end{tabular}

Figure 5 displays the $f_{c}$ measurements as a function of time at temperature (i.e., thermally aged specimens). Note that each data point was calculated utilizing individual specimens, and that the two curves share the same unaged, baseline specimen. These were not interrupted tests: the individual specimens were aged for the particular term and then afterwards analyzed using $\mathrm{AU}$. At both temperatures there appears to be a slight trend showing an increase in $f_{c}$, followed by a decrease, and then another increase. The average range for $f_{c}$ at both temperatures was 2.0 percent. This value was found by calculating the percent increase from the lowest to highest values of $f_{c}$ at each temperature. This range of values may be associated with the specimen-to-specimen variations since each data point was calculated using different specimens. Interrupted tests that follow the evolution of a single specimen are required in order to address this point.

\section{DISCUSSION AND CONCLUSIONS}

The AU technique appears to show promise as an NDE tool for empirically gauging the level of used up creep life in metallic alloys. Because of limitations in the specimen design, the sensitivity of the $\mathrm{AU}$ technique was not fully characterized. To gain further understanding the $\mathrm{AU}$ results need to be correlated to the microstructural changes experienced during creep and thermal aging. At this point, a relatively safe assumption could be made concerning the creep specimens. The AU parameters were probably altered as a result of increasing cavitation or porosity as the $100 \%$ creep life was approached. This was most notable when viewing the AU parameters measured at positions close to the fracture surface. Large changes in the measured $\mathrm{AU}$ response were seen at these locations. Currently, metallagraphic examinations of the tested specimens are being conducted. The results will explore, in detail, the relationship between the microstructural evolution and the $\mathrm{AU}$ response for both the creep tested and thermally aged conditions. A report of the findings will be published in the near future. In addition, the $\mathrm{AU}$ data indicated the potential for an empirical relationship that can be developed and utilized as a "before and after" measuring tool following the progression of damage within a single specimen. This recommendation for limiting the $\mathrm{AU}$ analysis to single specimens is the result of the specimen-to-specimen variations seen in Figure 3. These same material variations may have existed within the specimens and contributed to the inconsistencies seen in some of the data. Allowing the ultrasonic pulse to propagate through a larger amount of material may average out some of these material variations. For this

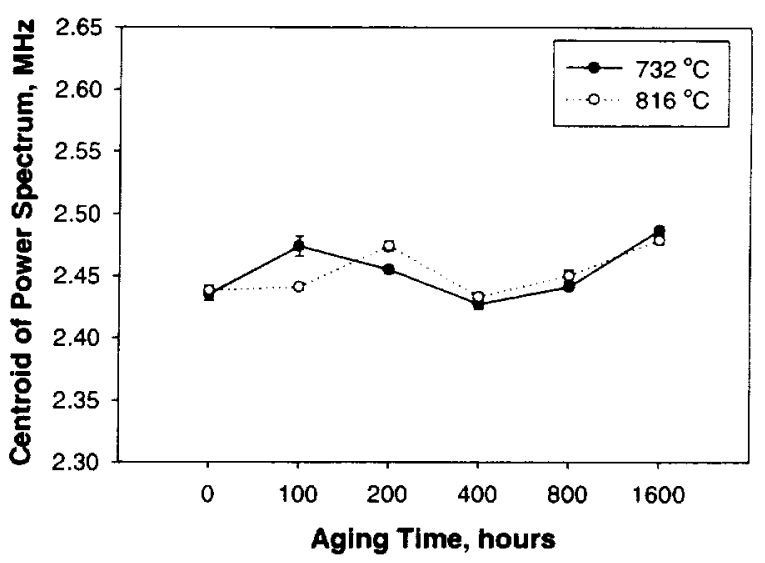

Figure 5. Centroid of power spectrum $\left(f_{c}\right)$ as a function of time at temperature (no load). Note that each data point represents a single specimen (5 specimens at $732{ }^{\circ} \mathrm{C}$, 5 specimens at $816{ }^{\circ} \mathrm{C}$, as well as a baseline specimen tested in the as recelved condition. The baseline specimen is represented at 0 aging time and is shared by both plots).

study, the length of ultrasonic propagation was limited by the size of the specimen's gage section.

In conclusion. the following achievements were accomplished during this study: A new user friendly, graphical interface AU system was developed that allowed for the simultaneous calculation of numerous AU parameters. Next, by employing a stepped, creep specimen design, (i.e., varying cross sectional area) it was shown that the $\mathrm{AU}$ technique has the potential for monitoring creep damage in metallic alloys. It was assumed that the increased cavitation or porosity due to accumulating creep damage induced changes in the ultrasonic attenuation as depicted by the various AU parameters. After studying the results, the centroid of the power spectrum was found to have the least scatter and the strongest relationship with used up creep life. The changes in the AU parameters were mainly attributed to the case of combined load and elevated temperature (i.e., creep) and not simply because of a timed exposure at elevated temperature (i.e., heat treatment or thermal aging). Although, thermal aging did cause a change in the $\mathrm{AU}$ parameters, these changes were smaller than those induced by creep testing. As noted in the Introduction, the $\mathrm{AU}$ technique has been extensively studied as a damage assessment tool for composite materials. Here, in addition to assembling the new AU software package, the AU technique has been expanded to the domain of metallic alloys.

In the future, it is imperative to analyze stepped specimens with additional levels of used up creep life. Such specimens would allow a more definite characterization of the sensitivity of the AU technique. Furthermore, various metallic systems with dissimilar failure mechanisms need to be studied. To achieve added confidence in an empirical AU creep life model, studies need to be conducted which analyze the effects of changing boundary conditions (e.g., effect of static or residual stress, temperature, transducer contact force, etc.). 


\section{REFERENCES}

I Lempp, W., Kasik. N., and Feller. U., "Nondestructive Degradation Evaluation of Ferritic Steels for High Temperature Applications," Nondestructive Characterization of Materials II. eds., J.F. Bussiere, J.P. Monchalin. C.O. Ruud, and R.E. Green Jr., Plenum Press, New York, 1987.

2 Shames, I.H. and Cozzarelli, F.A., "Elastic and Inelastic Stress Analysis." Prentice Hall, Englewood Cliffs, NJ, 1992.

3 Gittus, J., "Creep. Viscoelasticity and Creep Fracture in Solids." Applied Science Publishers LTD, London, 1975.

4 Kautz, H.E., "Determination of Plate Wave Velocities and Diffuse Field Decay Rates with Broadband Acousto-Ultrasonic Signals," Second Intemational Conference on AcoustoUltrasonics, ASNT, Atlanta, GA, 1993.

5 Tiwari, A.. "Real Time Acousto-Ultrasonic NDE Technique for Monitoring Damage in Ceramic Composites Under Dynamic Loads," NASA CR-198374, August 1995.

6 Weaver, R.L., "Diffuse Field Decay Rates for Material Characterization," Solid Mechanics Research for Quantitutive Nondestructive Evaluation, J.D. Achenbach and Y. Rajapaskie, eds., 1987, pp. 425-434.

7 Gyekenyesi, A.L.. "Isothermal Fatigue, Damage Accumulation, and Life Prediction of a Woven PMC," NASA CR-1998206593, March 1998.

8 Widmer, R., Dhosi, J.M., Mullendore, A., and Grant, N.J., "Mechanisms Associated with Long Time Creep Phenomena: Part I. Presentation of Creep Data and Structural Analysis," AFML-TR-65-181 Part 1.
9 Vary, A. and Bowles, KJ, "Ultrasonic Evaluation of the Strength of Unidirectional Graphite Polyimide Composites". Proceedings of the Eleventih Symposium on Nondestructive Testing. Southwest Research Institute, San Antonio, TX, 1977. pp 242-258.

10 Vary, A. and Bowles, KJ, "Use of Ultrasonic Acoustic Techniques for Nondestructive Evaluation of Fiber composite Strength". Proceedings of $33^{\prime \prime \prime}$ Amual Conference. SPI, New York, 1978, Section 24A, pp 1-5.

11 Kiernan, M.T, and Duke, J.C., "A Physical model for the Acousto-Ultrasonic Method," NASA CR-185294, October 1990.

12 Lott, L.A. and Kunerth, D.C., "NDE of Fiber-Matrix Interface Bonds and Material Damage in Ceramic/Ceramic Composites," Conference on Nondestructive Evaluation of Modern Ceramics. Columbus. OH, July 9-12. 1990, pp. 135-139.

13 Talreja. R., Govada, A., and Henneke, E.G., "Quantitative Assessment of Damage Growth in Graphite Epoxy Laminates by Acousto-Ultrasonic Measurements," Review of Progress in Quantitative Nondestructive Evaluation, Vol. 3. 1984. pp. 1099-1106.

14 Miller, I. and Freund. J.E., "Probability and Statistics for Engineers." 3rd ed., Prentice-Hall. Inc.. Englewood Cliffs, NJ. 1985. 


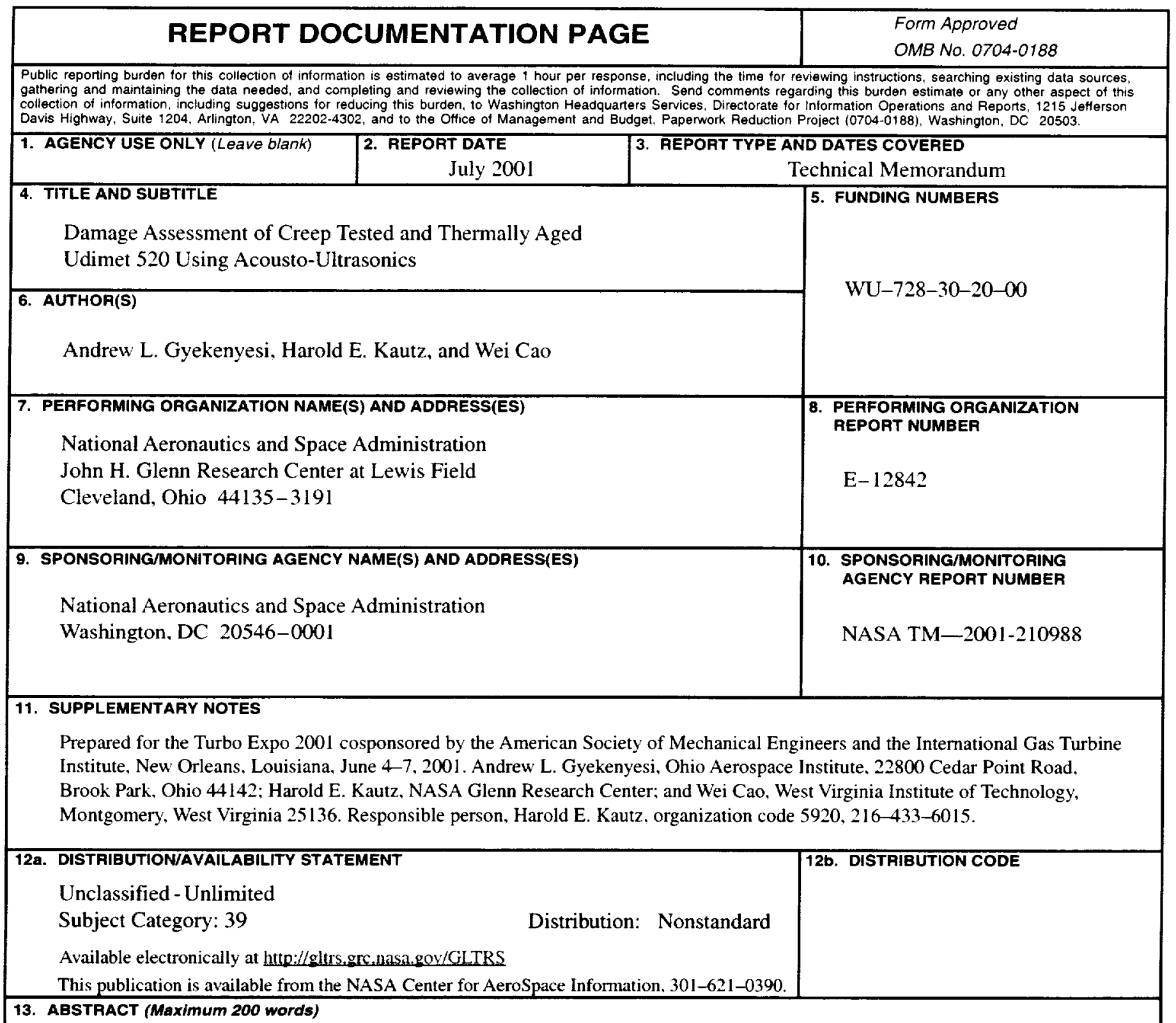

Due to elevated temperatures and excessive stresses, turbine components may experience creep behavior. As a result, it is desirable to monitor and assess the current condition of such components. This study employed the AcoustoUltrasonics $(A U)$ method in an effort to monitor the state of the material at various percentages of used up creep life in the nickel base alloy, Udimet 520. A stepped specimen (i.e., varying cross sectional area) was employed which allowed for a postmortem nondestructive evaluation (NDE) analysis of the various levels of used up life. The overall objectives here were two fold: First, a user friendly, graphical interface AU system was developed, and second the new AU system was applied as an NDE tool to assess distributed damage resulting from creep. The experimental results demonstrated that the AU method shows promise as an NDE tool capable of detecting material changes as a function of used up creep life. Furthermore, the changes in the AU parameters were mainly attributed to the case of combined load and elevated temperature (i.e., creep) and not simply because of a timed exposure at elevated temperature (i.e., heat treatment or thermal aging).

\section{SUBJECT TERMS}

Ultrasonics; Creep; Damage; NDE; Acousto-ultrasonics; Diffuse field decay rate

15. NUMBER OF PAGES

13

16. PAICE CODE

\begin{tabular}{|c|c|c|}
\hline $\begin{array}{c}\text { 17. SECURITY CLASSIFICATION } \\
\text { OF REPORT } \\
\text { Unclassified }\end{array}$ & $\begin{array}{c}\text { 18. SECUAITY CLASSIFICATION } \\
\text { OF THIS PAGE } \\
\text { Unclassified }\end{array}$ & $\begin{array}{c}\text { 19. SECURITY CLASSIFICATION } \\
\text { OF ABSTRACT } \\
\text { Unclassified }\end{array}$ \\
\hline
\end{tabular}

